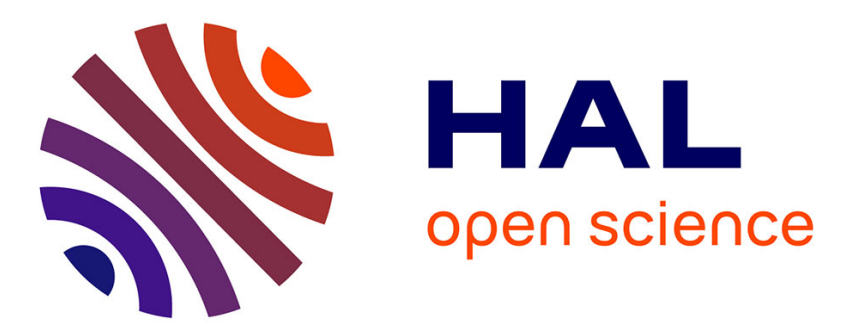

\title{
The Influence of Mode-Mixity on Dynamic Failure Mode Transitions in Polycarbonate
}

\author{
D. Rittel, R. Levin, H. Maigre
}

\section{To cite this version:}

D. Rittel, R. Levin, H. Maigre. The Influence of Mode-Mixity on Dynamic Failure Mode Transitions in Polycarbonate. Journal de Physique IV Proceedings, 1997, 07 (C3), pp.C3-861-C3-866. 10.1051/jp4:19973145 . jpa-00255433

\section{HAL Id: jpa-00255433 https://hal.science/jpa-00255433}

Submitted on 1 Jan 1997

HAL is a multi-disciplinary open access archive for the deposit and dissemination of scientific research documents, whether they are published or not. The documents may come from teaching and research institutions in France or abroad, or from public or private research centers.
L'archive ouverte pluridisciplinaire HAL, est destinée au dépôt et à la diffusion de documents scientifiques de niveau recherche, publiés ou non, émanant des établissements d'enseignement et de recherche français ou étrangers, des laboratoires publics ou privés. 


\title{
The Influence of Mode-Mixity on Dynamic Failure Mode Transitions in Polycarbonate
}

\author{
D. Rittel, R. Levin and H. Maigre* \\ Faculty of Mechanical Engineering, Technion, 32000 Haifa, Israel \\ * Laboratoire de Mécanique des Solides, URA N³17 du CNRS, École Polytechnique, \\ 91128 Palaiseau cedex, France
}

\begin{abstract}
The transition of a shear to opening type of failure mechanism has been reported for side impact experiments of notched or cracked plates (metallic alloys and polycarbonate). The present paper addresses additional aspects of the phenomenon in relation to mode-mixity for actual fatigue cracks in polycarbonate specimens. Two distinct experimental setups are used and systematically compared throughout the work: dominant mode II and dominant mode I loading. The experimental results show that the same characteristic failure mechanisms operate irrespective of the specimen geometry (loading mode) and crack-tip nature for a given impact velocity (evolution of the stress intensity factors)
\end{abstract}

Résumé. La transition des modes de rupture d’ouverture en cisaillement a été observée lors d'essais d'impact latéral de plaques entaillées ou fissurées (alliages métalliques et polycarbonate). Cet article traite d'autres aspects de la transition en relation avec la mixité du chargement pour des fissures de fatigue dans du polycarbonate. Nous utilisons et comparons systématiquement deux types d'expériences distinctes: chargement en mode II dominant ou en mode I dominant. Les résuitats montrent que des mécanismes de ruine identiques opèrent dans les deux cas, en fonction de la vitesse d'impact (evolution des facteurs d'intensité des contraintes) indépendemment de la géométrie de l'éprouvette ou de la nature de la fissure.

\section{INTRODUCTION}

Dynamic crack initiation addresses the case of a crack subjected to transient loading. The issue is the determination of a criterion for the onset of crack initiation and if possible an estimate of its initial trajectory. Whereas the problem has been extensively investigated in its theoretical aspects for the linear elastic case (Freund, 1990) a lot remains to be done at the experimental level to develop a sound criterion for dynamic crack initiation.

Considering materials related aspects of dynamic fracture, Charpy tests have long been used to investigate the ductile to brittle transition for crack opening mode. A new kind of failure mode transition has been reported for side impact of notched (and cracked) plates. In these experiments, a projectile is shot parallel to the notch direction, inducing mixed mode loading conditions with a dominant mode II term. Kalthoff (1988) investigated maraging steel and reported that at lower impact velocities, fracture proceeds in a "brittle" way by forming an angle of about $70^{\circ}$ with respect to the initial notch line. Increasing the impact velocity causes a shear band to develop and propagate for a short distance almost along the continuation of the original notch line. Lee and Freund (1990) studied this problem and provided an analytical solution for short times after impact such as to exclude wave reflections as a result of the specimen's finite size. They showed the development of a minor negative mode I component aside the dominant mode II. Ravi-Chandar (1995) worked on polycarbonate and he reported the very same behavior also in terms of a brittle to ductile transition and fracture angle $\left(66^{\circ}\right)$. Zhou et al. (1996) carried out a detailed investigation of side impact in maraging steel and a titanium alloy. They report a shear to opening (with an angle of about $30^{\circ}$ ) fracture mode transition in the maraging steel. The titanium specimens fail by shear mechanism only.

The cited works report about systematic shear band generation at the higher impact velocities with varying amounts of propagation and subsequent failure by opening mechanism at specific angles (either $70^{\circ}$ or $30^{\circ}$ ). These works address side impact experiments only with the crack-tip fields determined by using optical methods (caustics or CGS).

The present research addresses additional aspects of the problem with emphasis on the initiation process. We investigate actual cracks, grown experimentally as fatigue cracks and modeled numerically through contact and friction conditions. Since the problem is inherently related to mode-mixity, we systematically investigate and compare situations in which mode II is either the dominant (shear impact) or the minor mode (Ritte], Maigre and Bui, 1992). Failure modes are characterized using optical and scanning electron microscopy. The results are discussed and compared such as to outline the role of mode mixity in this kind of experiments in particular and in dynamic crack initiation more generally. 


\section{EXPERIMENTAL AND NUMERICAL FRAMEWORK}

\subsection{Experimental}

The experimental setup is of the "one point impact" type (Giovanola, 1986). It comprises the impacling apparatus and the specific specimen. A $12.7 \mathrm{~mm}$ diameter instrumented (PH 17-4) steel bar is on one side brought in contact with the specimen and on its other side is impacted by a striker fired by a gas gun. Typical impact velocities range from 8 to $60 \mathrm{~m} / \mathrm{s}$. Strikers with length of 8 or $17 \mathrm{~cm}$ were used to produce impacts of varying duration ( $30 \mu \mathrm{s}$ and $64 \mu \mathrm{s}$ respectively). The striker induces a compressive pulse in the bar which is partly transmitted to the specimen and partly reflected as a tensile pulse. The pulses were collected by means of a digital oscilloscope (Nicollet 490 model) at a sampling rate of $5 \mathrm{MHz}$. In some experiments, we cemented single wire fracture gages in the vicinity of the crack-tip to signal the onsel of crack-propagation. The experimental pulses were corrected for geometrical dispersion (Lifshitz and Leber. 1994) using home made programs. The interfacial force $P_{i}$ and velocity $V_{i}$ pulses were determined from the incident and reflected pulses.

Two kinds of specimens were used (Fig. 1): the rectangular plate, for shear impact ("mode II") experiments and the compact compression specimen (CCS) for "mode I" experiments (Rittel et al., 1992). Due to the asymmetrical loading, the crack-tip experiences mixed-mode conditions which were investigaled by Maigre and Rittel (1993) for the CCS.

Throughout the experiments, the specimen was brought in contact with the instrumented bar without special fixtures to support it so that fracture resulted from inertia only.

The boundary conditions (applied force and displacement) on the specimen are monitored through the instrumented bar, and they can be used for subsequent numerical simulations. In each specimen, a 2-3 $\mathrm{mm}$ long fatigue crack was grown carefully. The investigated material was polycarbonate, supplied as $12.7 \mathrm{~mm}$ thick sheets. The mechanical properties of this material were assessed using quasi static tensile testing. An equivalent "transfer modulus" (to account for dynamic effects - see Rittel and Maigre, 1996) was determined from longitudinal wave velocity measurements using ultrasonic technique. We also measured the quasi-static fracture toughness of the material using fatigue precracked CCS's (stroke control at a velocity of $0.2 \mathrm{~mm} / \mathrm{min}$ ). A representative value was found to be $\mathrm{K}_{\mathrm{IC}}=3.6 \mathrm{MPa} \cdot \mathrm{m}^{1 / 2}$.

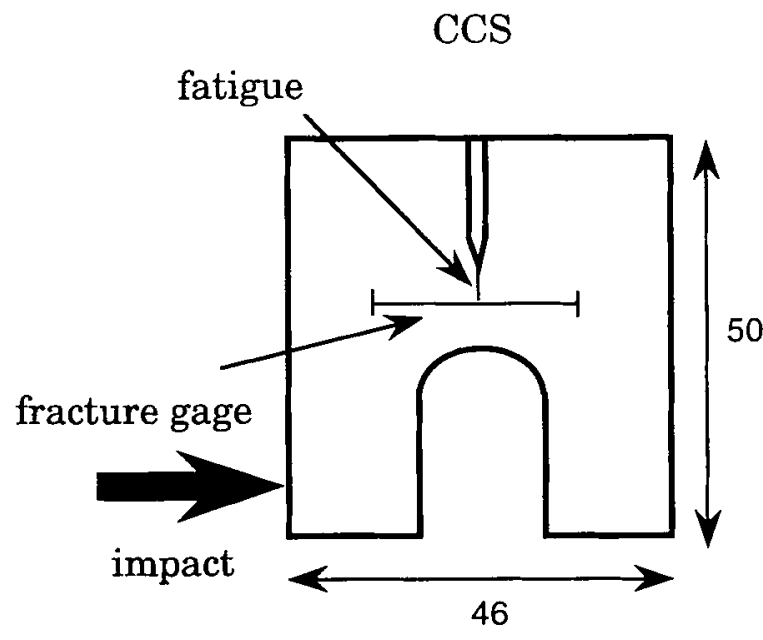

DOMINANT MODE I
SHEAR

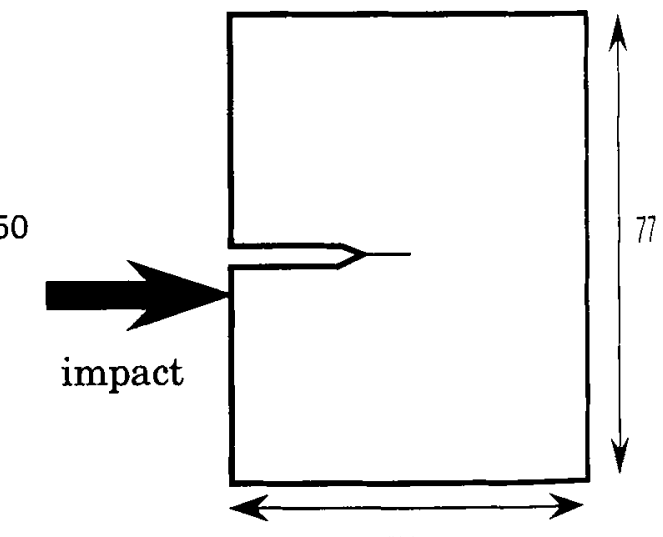

50

DOMINANT MODE I I

Figure 1: The specimens for dominant mode II and dominant mode I dynamic fracture testing 


\subsection{Numerical}

The crack-tip fields are not monitored directly in our experiments. Consequently, the stress intensity factors are determined from a numerical (finite element) model of actual experiments (hybrid experimentalnumerical approach). We assumed two-dimensional plane strain deformations and linear elastic material behavior. We did not include thermo-mechanical couplings as in Zhou et al. (1996) since the emphasis here is on the analysis of the crack-tip fields prior to initiation without attempting to model shear band related phenomena.

The crack tip is modeled using singular quarter point elements (Barsoum, 1978) and the crack in all the analyses is kept stationary so that the stress intensity factors are a function of time only (Freund, 1990). Traction free conditions are assumed over all the specimen except at the specimen-bar interface. To simulate the experiment, the recorded force pulse is applied to this interface as boundary condition. Once the specimen-bar separation has occurred, measurement of the interfacial forces and velocities using the instrumented bar is not possible as the specimen is no longer loaded through the input bar. However, the crack-tip fields can be assessed for any duration by extending the calculation while applying traction free conditions.

Fatigue cracks induce two specific conditions. The first is contact between the crack-flanks to avoid interpenetration following the negative mode I which develops for shear impact experiments (Lee and Freund, 1990). Secondly, friction may develop between the crack faces which affects the mode II component of the crack-tip loading. Contact was modeled using special contact elements which apply a normal reaction when the gap between the two surfaces is closed (ANSYS, 1994). Friction was modeled as Coulomb friction and the coefficient of friction in all the analyses was arbitrarily fixed to $\mu \mathrm{s}=0.4$. The equations of equilibrium were solved using Newmark implicit scheme (Bathe, 1982). The mode I and mode II stress intensity factors were determined from the displacements "measured" at two control points in the vicinity of the crack-tip (Bui et al., 1992).

\section{RESULTS}

\section{Foreword}

The framework described here is a joint experimental-numerical effort. A detailed report and discussion of our results is in preparation. In this paper, we will describe selected results of the work.

\subsection{The influence of contact and friction}

The influence of friction and contact on the stress intensity factors in our specimens was assessed by applying a gaussian pressure pulse $\left(30 \mu \mathrm{s}\right.$ wide $-2 \times 10^{7} \mathrm{~Pa}$ at peak) to simulate transient loading characteristic of that applied in typical experiments. Fig. 2 shows the evolution of $\mathrm{K}_{\mathrm{I}}$ and $\mathrm{K}_{\mathrm{II}}$ (whose absolute values are meaningless) for a shear impact specimen to which we prescribed contact conditions with $\mu=0$ (frictionless) and $\mu=0.4$.
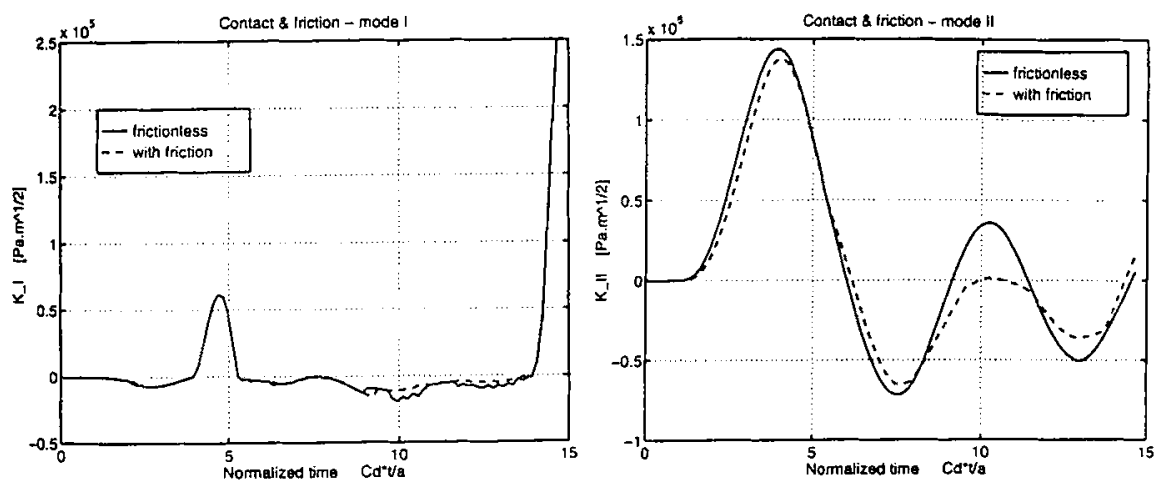

Figure 2: Results of a numerical simulation. Mode I and II stress intensity factors for contact (w/o friction) conditions on the fatigue crack. 
This figure shows that contact does not allow for the negative mode I to develop while friction does not seem to affect crack opening (the slightly negative $\mathrm{K}_{\mathrm{I}}$ values are most likely related to the contact stiffness used in the numerical calculations). As the time increases ( $\left.t_{\text {norm }}>10\right)$ a marked tendency for crack opening develops. On the other hand, the influence of friction is felt on the mode II in the sense that contact tends to restrain the shearing motion of the crack faces, but this is mostly evidenced at the later times $\left(t_{\text {norm }}>10\right)$. It should be noted that the absence of a negative mode I component during a large initial time brings this experiment close to a "pure mode II" condition.

\subsection{Shear experiments ("mode II")}

A total of 16 specimens were tested. We observed that there is a range of velocities (the "lower impact velocities", e.g., below $25 \mathrm{~m} / \mathrm{s}$ ) for which the specimen fractures whereas in another range (the "higher impact velocities", e.g., $60 \mathrm{~m} / \mathrm{s}$ ) an adiabatic shear band is observed and the crack does not seem to grow (Rittel et al., 1997). Shear bands are clearly detected by visual examination only on specimens subjected to the high impact velocities. This result is similar to previously reported results on failure mode transitions (e.g., Ravi-Chandar 1995).

It can also be noted that regardless of the kind of the crack-tip, all the specimens which fractured (11) out of 16) did it at angles which did not exceed $40^{\circ}$. This value must be contrasted with the predicted value of $70^{\circ}$ at which maximum tensile stress develops for mode II loading. Consequently, opening at such an angle suggests the joint operation of not only mode II but also mode I fracture mechanism as discussed later.

\subsection{Compact compression experiments ("mode I")}

A total of 8 specimens were tested. Here, fracture occurred in every case. However, similar to the shear impact experiments, the maximum kink angle does not exceed $40^{\circ}$ regardless of the impact velocity.

\subsection{Fractographic analysis \\ 3.4.1 Shear impact specimens}

The high velocity impact is characterized by a shear band which develops at the crack-tip but does not propagate significantly in our experiments. The shear band appears as a planar zone, 1-2 mm long, which spans across the specimen's width (Rittel et al., 1997). This band is best detected by tilting the specimen with respect to the incident light and carefully looking in the vicinity of the crack-tip. Optical microscopy at relatively low magnifications discloses minor extension of the fatigue crack within the shear band but this crack did not propagate much either and its tip appears to be quite blunted. Fractographic examination in the scanning electron microscope discloses a layered pattern which is characteristic of the band. This pattern is followed by a series of waves emanating concentrically from the shear band (Fig. 3a). The overall size of the band and the waves is of the order of the millimeter.

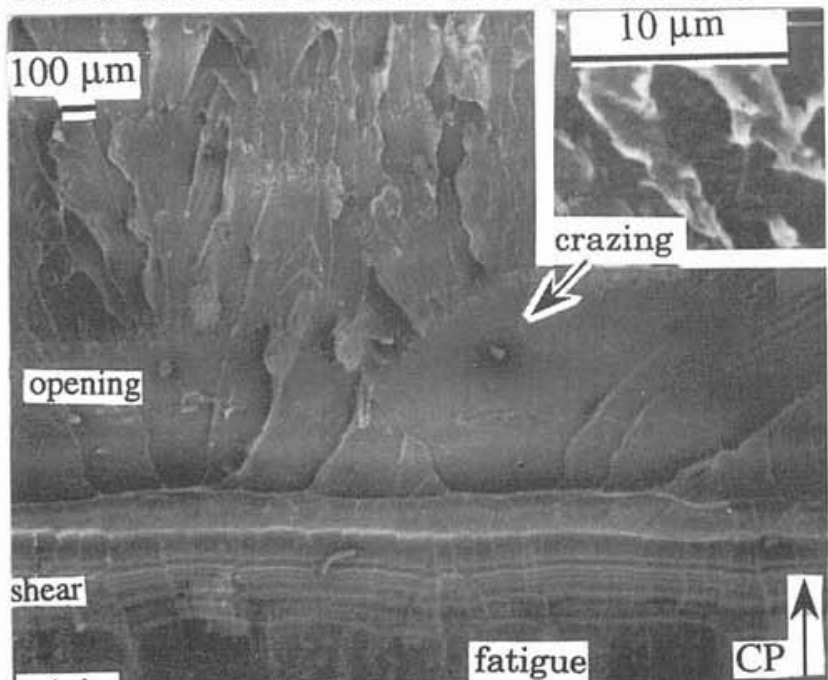

(a)

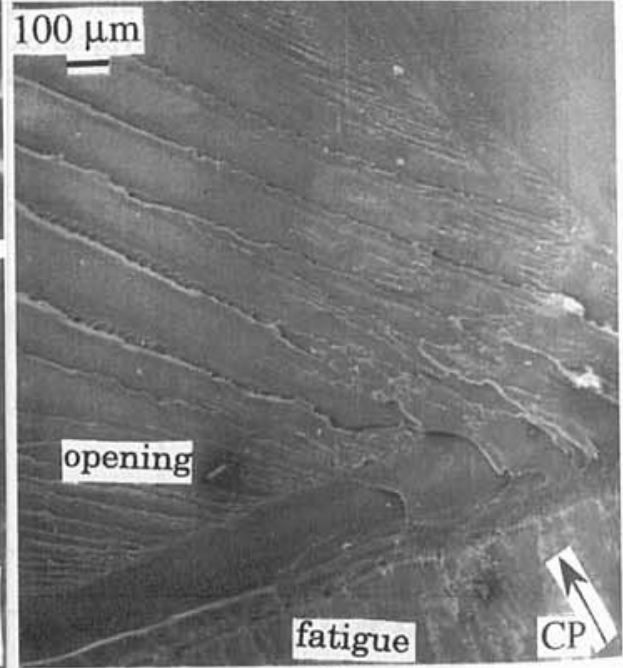

(b)

Figure 3: SEM fractographs of (a) high and (b) low velocity impacted shear specimens ("mode II") 
The fracture surface topography in the waves appears to be featureless at low magnifications but inspection at higher magnifications reveals a characteristic fine scaled pattern of alternating patches of material over a uniform background. These patches can be attributed to the operation of a crazing mechanism sensitive to normal stresses. (Kausch, 1987).

Further apart, the fracture surface is much rougher. Yet, higher magnifications show again a lack of distinctive features.

The fracture surface typical of a lower velocity impact is shown in Fig. 3b. The fracture comprises two main features: arrays of linear markings which converge to the fatigue crack. These arrays delineate a seemingly featureless zone although patches of striations can somehow be discerned. Further examination at higher magnification clearly shows that the striations are made of alternating patches identical to those observed in the previous specimen. No shear band was observed as in the previous case.

\subsubsection{Compact compression specimens}

A typical fractograph of higher velocity impact in a compact compression specimen is shown in Fig. 4a. Fracture begins by a shear band with its characteristic pattern of parallel striations. Higher magnifications reveal the characteristic layered aspect of the fracture surface in the band. The band extends by a series of waves within which one can observe the alternating patches of material, both features similar to those observed in the side impact specimen. Farther away, the fracture surface is very rough, quite similar to the observations of the previous specimen.

A typical fractograph of lower velocity impact in a compact compression specimen is shown in Fig. 4b. In the immediate vicinity of the fatigue crack, filaments are noticeable (similar to the previously mentioned linear features) and the general fracture surface topography seems once again rather dull at low magnifications, whereas at higher magnifications, craze markings are again observed. The fracture surface topography comprises rough features farther away from the initiation area.

The fractographic observations can thus be summarized at this stage as follows. A high degree of similarity of the fractographic features can be noted between our "mode II" and "mode I" specimens. Specifically, at "lower" velocities shear bands are not observed. The fracture surface looks dull at low magnifications while at high magnifications a typical pattern of alternating patches (craze dominated fracture) of material is noted. For the higher velocity impacts at which a shear band is formed (with evidence of local heating), the latter extends by a series of wavy patterns emanating form its front. These patterns comprise the above mentioned alternating patterns of patches followed by very rough features.

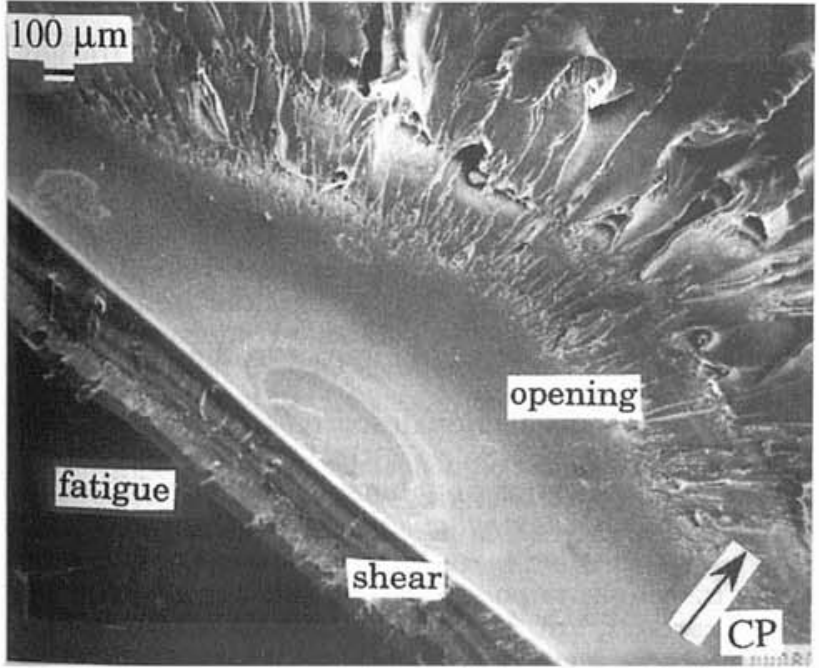

(a)

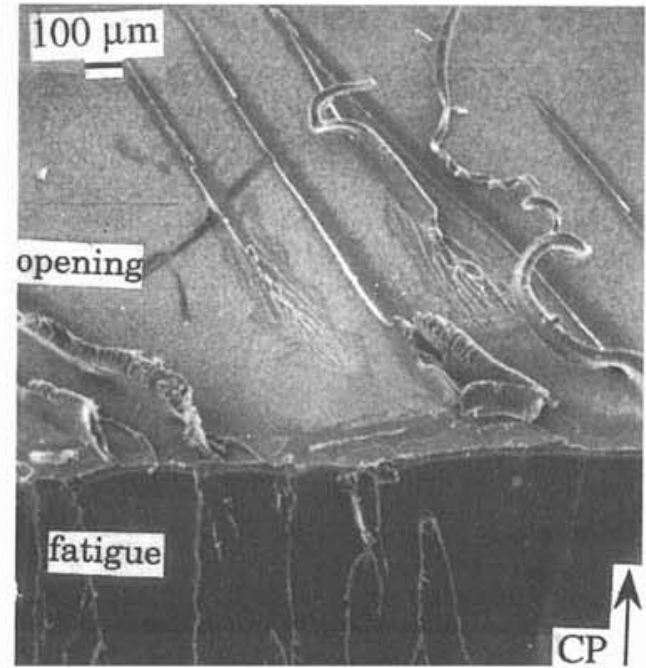

(b)

Figure 4: SEM fractographs of (a) high and (b) low velocity CC specimens ("mode I")

The key point here is that these characteristic features are observed regardless of the specimen and/or experiment in question. 


\section{DISCUSSION AND CONCLUSIONS}

The investigation has been carried out along three complementary axes: mechanical (dynamic fracture tests) - materials related (fracture mechanisms) - and numerical. A relatively large sample size of dominant mode II and dominant mode I specimens have been systematically tested.

The experiments reported here all involve mixed-mode loading to some extent. Not only do these experiments confirm the previously reported trend for failure mode transition but they also shed additional light on its operation in various contexts.

A first observation is that transition of failure modes is not related to the nature of the crack-tip (notch or fatigue crack). The selection of a failure mode is thus not sensitive to the level of negative mode I which develops in side-impact experiments.

The important point in our "mode II" experiments is that the crack tip experiences initially almost "pure mode II" conditions followed by mixed-mode loading at the later stages. Shear band initiation, propagation and final fracture are thus separable events in this experiment.

The initiation phase of dynamic cracking with the occurrence (or lack) of adiabatic shear banding is the characteristic response of a material which possesses a sensitivity to two distinct failure modes, shearing and opening. As a remark, the same experiment carried out on a brittle polymer - characterized by a single failure mode (opening) - always yieids fracture at about $70^{\circ}$.

The occurrence of shear bands is neither restricted to a specific kind of experiment nor to the crack-tip geometry. This point was corroborated by the striking similarity of fractographic features between mode Il and mode I specimens at matching impact velocities.

Consequently, mixed-mode loading causes the joint operation of shear and opening fracture mechanisms At high impact velocities, the shear failure mechanism is operative and it does not contribute significantly at lower impact velocities. This important cooperation of failure mechanisms should be accounted for when proposing a criterion for dynamic crack initiation.

\section{Acknowledgment}

Support from Arc-en-Ciel cooperation program is gratefully acknowledged. D.R. wishes to acknowledge financial support from the Israel Science Foundation and from the Technion Fund for Research Promotion.

\section{References}

ANSYS, User's Manual, (1994), Swanson Analysis Systems Inc.

Barsoum, R.S., (1978), "On the use of isoparametric finite elements in linear elastic fracture mechanics", Int. J. Num. Methods in Eng., 10, 25-37.

Bui, H.D., Maigre, H. and Rittel, D. (1992). "A new approach to the experimental determinalion of the dynamic stress intensity factor., Int. J. Solids Structures, 29, No. 23, 2881-2895.

Freund, L.B., (1990), Dynamic Fracture Mechanics, Cambridge University Press, Cambridge.

Giovanola, J.H., (1986), "Investigation and application of the one-point-bend impact test, ASTM STP 905, ASTM, Philadelphia, PA.

Kalthoff, J.F. (1988), Shadow optical analysis of dynamic fracture, Optical Engng, 27, 835-840.

Kausch, H.H., (1987), Polymer Fracture, 2nd ed., Springer-Verlag, Berlin.

Lee, Y.J. and Freund, L.B. (1990), Fracture initiation due to asymmetric impact loading of an edge cracked plate. J. Appl. Mech. 57, 104-111.

Lifshitz, J.M. and Leber, H., (1994), Data processing in the split Hopkinson pressure bar tests, Int. J. Impact Engng., 15, No. 6, 723-733.

Maigre, H. and Rittel, D., (1993), "Mixed-mode quantification for dynamic fracture initiation: application to the compact compression specimen", International Journal of Solids and Structures, 30. No. 23, 3233-3244.

Ravi Chandar, K., (1995), "On the failure mode transitions in polycarbonate under dynamic mixed mode loading", International Journal of Solids and Structures, Vol. 32 No. 6/7, 925-938.

Rittel, D., Maigre, H and Bui, H.D., (1992), A new method for dynamic fracture toughness testing, Scripta Metallurgica et Materialia, 26, 1593-1598.

Rittel, D., Levin, R. and Maigre, H., (1996), "On dynamic crack initiation in polycarbonate under mixed-mode loading", Mechanics Research Communications, Vol. 24, No. 1, 57-64.

Zhou, M., Rosakis, A.J. and Ravichandran, G., (1996), Dynamically propagating shear bands in impact-loaded prenotched plates. I- Experimental investigations of temperature signatures and propagation. speed, J. Mech. Phys. Solids, 44, No. 6, 981-1006. 